\title{
Intra-Amygdala Blockade of the NR2B Subunit of the NMDA Receptor Disrupts the Acquisition But Not the Expression of Fear Conditioning
}

\author{
Sarina M. Rodrigues, Glenn E. Schafe, and Joseph E. LeDoux \\ W. M. Keck Foundation Laboratory of Neurobiology, Center for Neural Science, New York University, New York, \\ New York 10003
}

The lateral nucleus of the amygdala (LA) is an essential component of the neural circuitry underlying Pavlovian fear conditioning. Although blockade of NMDA receptors in LA and adjacent areas before training disrupts the acquisition of fear conditioning, blockade before testing also often disrupts the expression of fear responses. With this pattern of results, it is not possible to distinguish a contribution of NMDA receptors to plasticity from a role in synaptic transmission. In past studies, NMDA blockade has been achieved using the antagonist D, L2-amino-5-phosphovalerate, which blocks the entire heteromeric receptor complex. The present experiments examined the effects of selective blockade of the NR2B subunit of the
NMDA receptor in LA using the selective antagonist ifenprodil. Systemic injections of ifenprodil before training led to a dosedependent impairment in the acquisition of auditory and contextual fear conditioning, whereas injections before testing had no effect. Intra-amygdala infusions of ifenprodil mirrored these results and, in addition, showed that the effects are attributable to a disruption of fear learning rather than a disruption of memory consolidation. NMDA receptors in LA are thus involved in fear conditioning, and the NR2B subunit appears to make unique contributions to the underlying plasticity.

Key words: fear; learning; amygdala; NMDA receptor; NR2B subunit; ifenprodil
The lateral nucleus of the amygdala (LA) is an essential component of the neural circuit underlying Pavlovian fear conditioning and also appears to be a crucial site of plasticity in this circuitry (Fanselow and LeDoux, 1999; LeDoux, 2000). Nevertheless, the synaptic mechanisms in LA mediating fear conditioning remain controversial.

Building on the role of NMDA receptors in long-term synaptic potentiation (LTP) in the CA1 region of the hippocampus (for review, see Bliss and Collingridge, 1993; Malenka and Nicoll, 1999), a number of studies have assessed whether blockade of NMDA receptors in LA and adjacent areas, especially the basal nucleus (B), would interfere with fear conditioning (Miserendino et al., 1990; Campeau et al., 1992; Fanselow and Kim, 1994; Lee and Kim, 1998). These studies have consistently found that blockade of NMDA receptors in LA and B before training prevents the acquisition of fear conditioning, suggesting that NMDA receptors mediate synaptic plasticity during learning. However, several of these studies have also found that NMDA receptor blockade before testing prevents the expression of previously conditioned responses (Maren et al., 1996; Lee and Kim, 1998; Lee et al., 2001). These observations suggest that the effects of NMDA blockade on acquisition could be attributable to a disruption of routine synaptic transmission instead of, or in addition to, a disruption of plasticity. Indeed, a number of reports have demonstrated the involvement of NMDA receptors in routine synap-

Received Jan. 26, 2001; revised June 11, 2001; accepted June 11, 2001.

This research was supported in part by National Institute of Mental Health Grants R01 MH 46516, R37 MH 38774, and P50 MH 58911. This work was also supported by a grant from the W. M. Keck Foundation to New York University.

Correspondence should be addressed to Dr. Joseph E. LeDoux, Center for Neural Science, New York University, 4 Washington Place, Room 809, New York, NY 10003. E-mail: ledoux@cns.nyu.edu.

Copyright (ㄷ) 2001 Society for Neuroscience $\quad 0270-6474 / 01 / 216889-08 \$ 15.00 / 0$ tic transmission in LA and B (Li et al., 1995, 1996; Maren, 1996; Weisskopf and LeDoux, 1999). Collectively, this pattern of findings makes it difficult to accept the conclusion that NMDA blockade during learning only disrupts plasticity.

NMDA receptors are heteromeric complexes composed of several subunits (Nakanishi, 1992; Hollmann and Heinemann, 1994). The NR1 subunit is required for channel function, whereas certain NR2 subunits, especially the NR2A and NR2B subunits, regulate channel gating (Moyner et al., 1992). Past studies of fear conditioning have used the NMDA antagonist D,L-2-amino-5-phosphovalerate (APV), which disrupts the entire receptor complex (Watkins and Olverman, 1987). Thus, it might be possible to disrupt acquisition but not expression of fear conditioning by using an antagonist with partial and selective effects on individual channel subunits. In vitro studies have shown that the NR1-NR2B complex exhibits longer EPSPs than the NR1-NR2A complex (Moyner et al., 1994), allowing a longer time window for coincidence detection in the former. Given that coincidence detection is believed to be an important function performed by NMDA receptors during learning (Tsien, 2000), the NR2B subunit may be especially important during plasticity. Indeed, during early development, a time during which much plasticity occurs, the NR2B subunit is especially prevalent (Sheng et al., 1994; Portera-Cailliau et al., 1996). Furthermore, tyrosine phosphorylation of NR2B has been correlated with both synaptic plasticity in the hippocampus and taste learning in the insular cortex (Rosenblum et al., 1996, 1997; Rostras et al., 1996), and transgenic overexpression of the NR2B subunit in mice enhances learning in several tasks, including fear conditioning (Tang et al., 1999). In the present study we therefore examined whether ifenprodil, a selective antagonist of the NR2B subunit (Chenard and Menniti, 1999), would disrupt the acquisition but not the expression of fear conditioning in rats. We first tested this with systemic 
injections of ifenprodil and then turned to infusions targeted to LA.

\section{MATERIALS AND METHODS}

Subjects. Subjects were adult male Sprague Dawley rats (Hilltop Laboratories, Scottdale, PA). They were housed individually in plastic Nalgene cages and placed on a $12 \mathrm{hr}$ light/dark cycle. Food and water were provided ad libitum throughout the experiment. All procedures were in accordance with the National Institutes of Health Guide for the Care and Use of Experimental Animals and were approved by the New York University Animal Care and Use Committee.

Surgery. Rats were anesthetized with a mixture of ketamine (100 $\mathrm{mg} / \mathrm{kg}$, i.p.; Ketaset; Phoenix, St. Joseph, MO), xylazine (6.0 mg/kg, i.p.; Xyla-Jet; Phoenix), and medetomidine $(0.5 \mathrm{mg} / \mathrm{kg}$, i.p.; Domitor; Pfizer, New York, NY). Using a stereotaxic apparatus, guide cannulas (22 gauge; Plastics One, Roanoke, VA) fitted with internal cannulas that extended out $1.5 \mathrm{~mm}$ from the base of the guide were positioned just above LA using the following coordinates from Paxinos and Watson (1986): $2.8 \mathrm{~mm}$ posterior to bregma, $5.3 \mathrm{~mm}$ lateral to the midline, and $8.0 \mathrm{~mm}$ ventral to the skull surface. The guide cannulas were fixed to screws in the skull with dental cement. Internal cannulas were replaced with dummy cannulas, cut $0.5 \mathrm{~mm}$ longer than the guide cannulas, to prevent clogging. After surgery, rats were administered butorphanol tartrate $(2.0 \mathrm{mg} / \mathrm{kg}$, i.p.; Torbugesic; Fort Dodge Laboratories, Fort Dodge, IA) and atipamezole $(1.0 \mathrm{mg} / \mathrm{kg}$, i.p.; Antisedan; Pfizer, New York, NY) for analgesia and reversal of the anesthetic. Rats were given at least $5 \mathrm{~d}$ to recover before experimental procedures.

Drug administration. For experiments testing the effects of ifenprodil via systemic administration, rats were given intraperitoneal injections. Ifenprodil (Sigma, St. Louis, MO) was dissolved in vehicle (0.1 M PBS, $0.1 \%$ tartaric acid) at varying concentrations to obtain a constant injection volume of $\sim 2.5 \mathrm{ml} / \mathrm{kg}$ for each rat. This was done to keep the amount of solution injection constant to control for potential effects of the vehicle alone. Injections of vehicle or drug solution were given $15 \mathrm{~min}$ before conditioning and testing.

In studies involving intra-amygdala infusions, rats were held gently in the experimenter's lap while dummy cannulas were exchanged with 28 gauge infusion cannulas. The cannulas were connected to $1.0 \mu \mathrm{l} \mathrm{Hamil-}$ ton syringes via polyurethane tubing. The tubing was back-filled with sesame oil, with a small air bubble separating the oil from the drug solution. Drugs were infused bilaterally with an infusion pump at a rate of $0.25 \mu \mathrm{l} / \mathrm{min}$. A total volume of $0.5 \mu \mathrm{l}$ of an ifenprodil drug solution or vehicle (0.1 M PBS, $0.1 \%$ tartaric acid) was infused into each amygdala. After infusion, the cannulas were left in place for an additional $1 \mathrm{~min}$ to allow the solution to diffuse away from the cannula tip. The dummy cannulas were then replaced and the rat was returned to its home cage. Infusions occurred 15-30 min before conditioning and testing.

Apparatus. Pavlovian fear conditioning took place in a Plexiglas conditioning chamber with a metal grid floor (model E10-10; Coulbourn Instruments, Lehigh Valley, PA), dimly lit with a single house light and enclosed within a sound-attenuating chamber (model E20). Testing for auditory fear conditioning occurred in a distinct Plexiglas chamber (ENV-001; MedAssociates, Georgia, VT) to minimize generalization from the conditioning environment. The tone testing chamber was brightly lit with three house lights and contained a black Formica floor that had been washed with a peppermint soap. A microvideocamera mounted at the top of the chambers allowed videotaping during auditory fear testing for later scoring. Testing for contextual conditioning took place in the same chamber as fear conditioning.

Fear conditioning procedure. On the day before conditioning (day 1), rats were habituated to the training and testing chambers for a minimum of $10-15 \mathrm{~min}$. Habituation was counterbalanced between groups to control for possible order effects. On the day of conditioning (day 2), rats were injected with drug or vehicle and given 2-3 min to acclimate to the conditioning chamber. This was followed by the presentation of five pairings of a $20 \mathrm{sec}$ tone conditioned stimulus $(\mathrm{CS})(5 \mathrm{kHz}, 75 \mathrm{~dB})$ that coterminated with a foot shock unconditioned stimulus (US) $(0.5 \mathrm{sec}, 0.5$ $\mathrm{mA}$ ). The intertrial interval (ITI) varied randomly between 90 and 120 sec. After conditioning, rats were returned to their home cages and to the colony.

To assess possible effects of ifenprodil on shock sensitivity, rats were observed throughout the training procedure. No differences in reactivity to the shock US were observed. Rats were observed to run, jump, and/or vocalize normally to the shock (our unpublished observations).

Testing of conditioned fear responses. Approximately $24 \mathrm{hr}$ after condi- tioning, long-term memory (LTM) of fear responses conditioned to the tone CS and the conditioning apparatus (context) were separately tested. Responses conditioned to the tone CS were measured in the novel test chamber (see above). After a brief acclimation period to the test chamber, the rats received five test tones $(20 \mathrm{sec}, 5 \mathrm{kHz}, 75 \mathrm{~dB}$; ITI, $100 \mathrm{sec})$. Then, they were placed in the conditioning chamber and allowed to explore for $5 \mathrm{~min}$ to allow them time to recognize the context, after which the duration of freezing was measured every other $30 \mathrm{sec}$ for an additional $5 \mathrm{~min}$. Testing for tone and contextual memory was counterbalanced within groups to control for possible order effects.

In some studies, an additional test of short-term memory (STM) was performed $1 \mathrm{hr}$ after fear conditioning. Conditioning to the tone and context were separately assessed, as described above, and as before the order of the tone and context was counterbalanced. In the STM test of conditioning to the tone, only three test tones were used to minimize extinction. The context and tone STM tests were approximately the same total length (10 min).

Histology. To verify injector tip location in the intra-amygdala infusion experiments, rats were anesthetized with an overdose of chloral hydrate $(600 \mathrm{mg} / \mathrm{kg}$, i.p.) and perfused transcardially with $10 \%$ buffered formalin. The brains were post-fixed in $30 \%$ sucrose in $10 \%$ buffered formalin and subsequently blocked, sectioned on a cryostat or microtome at 50 $\mu \mathrm{m}$, and stained for Nissl with thionin. Sections were coverslipped with Permount and examined under light microscopy for injector tip penetration into the amygdala.

\section{RESULTS}

We first determined whether systemic administration of the NR2B antagonist ifenprodil would affect the acquisition and/or expression of fear conditioning. This study was then repeated with infusions of ifenprodil through cannulas targeted for LA. The intra-amygdala study was subsequently replicated with the addition of a test of STM to determine whether NR2B receptor blockade in the amygdala prevents the learning or the consolidation of fear conditioning. For each series of experiments, freezing scores across trials did not significantly differ and were therefore averaged for each rat into a single score. Scores were then expressed as a percentage of total CS presentation or observation time. All data were analyzed using ANOVA and Duncan's multiple range post hoc $t$ tests.

\section{Systemic injections of ifenprodil}

In the first series of experiments, separate groups of rats were given injections of vehicle or one of three doses of ifenprodil (1.0, 3.0 , or $10.0 \mathrm{mg} / \mathrm{kg}$, i.p.) either before training or before a testing session that took place $\sim 24 \mathrm{hr}$ after training (for a total of eight groups). Animals in the pretraining infusion groups received either ifenprodil or vehicle immediately before fear conditioning and then received vehicle injections immediately before testing. Animals in the pretesting infusion groups received vehicle injections before training and then received one of the doses of ifenprodil or vehicle immediately before testing.

\section{Pretraining injections}

Pretraining injections of ifenprodil produced a dose-dependent decrease in the amount of freezing elicited by the tone CS (Fig. $1 A)$. The ANOVA showed a significant effect for group $\left(F_{(3,30)}=\right.$ 20.68; $p<0.01$ ), and post hoc $t$ tests showed a significant difference between the vehicle and each of the ifenprodil groups, as well as between the group that received the highest dose of ifenprodil compared with groups that received the lower doses $(p<0.05)$. The contextual memory test led to a similar pattern of results. The ANOVA for contextual memory scores showed a significant effect for group $\left(F_{(3,30)}=8.93 ; p<0.001\right)$, and post hoc $\mathrm{t}$ tests showed a significant difference between the vehicle and ifenprodil groups for observation periods $(p<0.01)$. 
A.

\section{Pretraining Injections}

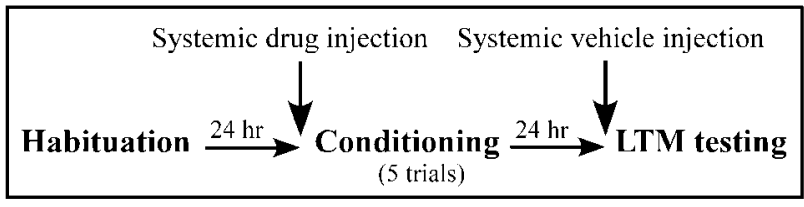

TONE MEMORY

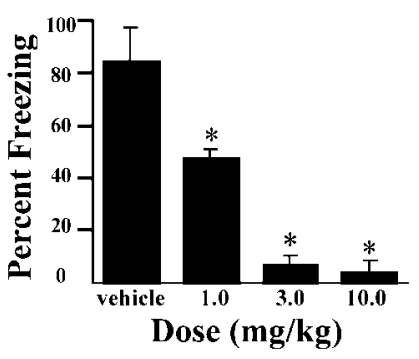

CONTEXTUAL MEMORY

\section{B.}
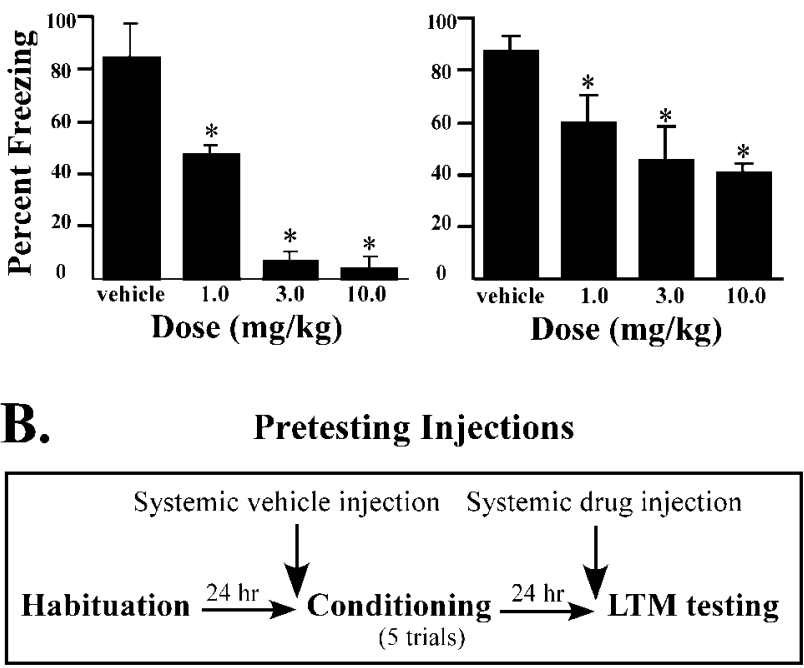

TONE MEMORY

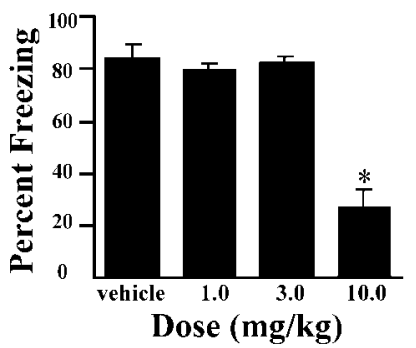

CONTEXTUAL MEMORY

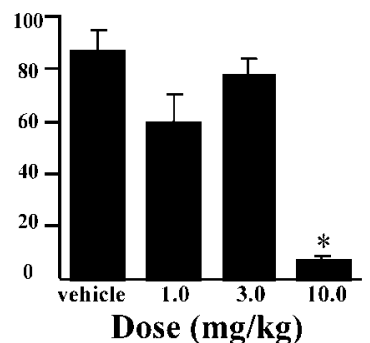

Figure 1. Effects of systemic injections of ifenprodil on LTM. A, Top, Outline of general behavioral procedures for pretraining systemic intraperitoneal injections of ifenprodil. Bottom, Mean $( \pm S E)$ percentage freezing for tone and contextual LTM in rats injected with vehicle $(n=10), 1.0$ $\mathrm{mg} / \mathrm{kg}$ ifenprodil $(n=8), 3.0 \mathrm{mg} / \mathrm{kg}$ ifenprodil $(n=8)$, or $10.0 \mathrm{mg} / \mathrm{kg}$ ifenprodil $(n=8)$ before training. B, Top, Outline of general behavioral procedures for pretesting systemic intraperitoneal injections of ifenprodil. Bottom, Mean ( \pm SE) percentage freezing for tone and contextual LTM in rats injected with vehicle $(n=10), 1.0 \mathrm{mg} / \mathrm{kg}$ ifenprodil $(n=8), 3.0 \mathrm{mg} / \mathrm{kg}$ ifenprodil $(n=8)$, or $10.0 \mathrm{mg} / \mathrm{kg}$ ifenprodil $(n=8)$ before testing. ${ }^{*} p<$ 0.05 relative to vehicle.

\section{Pretesting injections}

Ifenprodil injections before testing produced a different pattern of results (Fig. $1 B$ ). For tone memory, the ANOVA revealed a significant effect for group $\left(F_{(3,30)}=87.03 ; p<0.01\right)$, but post hoc $t$ tests showed that this effect was due only to impairments in the highest dose group $(p<0.01)$. The other two doses, each of which significantly impaired acquisition, had no effect on the expression of previously conditioned auditory fear $(p>0.05)$. The ANOVA for contextual memory scores also showed an effect $\left(F_{(3,30)}=59.83 ; p<0.01\right)$. However, as in the auditory test, this effect was observed only in the group receiving the highest dose $(p<0.05)$. As before, the two lower doses of ifenprodil, which were effective at blocking the acquisition of contextual fear, failed to block expression $(p>0.05)$. Thus, doses of ifenprodil sufficient to block acquisition of fear conditioning have no effect on performance. Only the highest dose affected both acquisition and performance.

\section{Intra-amygdala infusions of ifenprodil}

To determine whether the effects of systemic administration of ifenprodil might be attributable to an action in LA, rats were prepared with bilateral cannula implants aimed for LA. After recovery, separate groups of rats received local infusions of ifenprodil (1.0 or $0.1 \mu \mathrm{g}$ ) or vehicle either before training or before testing using the same basic design as in the systemic study above.

\section{Pretraining injections}

Ifenprodil infusion before conditioning produced a dosedependent impairment in freezing for both tone and context memory (Fig. $2 A$ ). The ANOVA for tone memory scores showed a significant effect for group $\left(F_{(2,21)}=120.3 ; p<0.001\right)$, and post hoc $t$ tests showed that the two ifenprodil groups differed from the vehicle group $(p<0.01)$. Furthermore, less freezing occurred in the high-dose group than in the low-dose group $(p<0.05)$, indicating a dose-dependent effect of ifenprodil in LA. In the test of contextual conditioning, pretraining inf usions also produced a significant effect for group $\left(F_{(2,21)}=62.55 ; p<0.001\right)$, and post hoc $t$ tests again showed that the two ifenprodil groups froze significantly less than the vehicle group $(p<0.01)$.

\section{Pretesting injections}

Intra-amygdala infusions before testing did not produce a significant impairment in freezing for either tone or contextual conditioning (Fig. $2 B$ ). The ANOVA for either test showed no significant effects for group $(p>0.05)$. Thus, consistent with the findings of the experiments using systemic administration, intraamygdala infusion of ifenprodil impairs acquisition but not expression of fear conditioning.

\section{Effects of intra-amygdala infusions of ifenprodil on short-term versus long-term memory}

In the studies described above, pretraining infusions of ifenprodil led to a failure to form a LTM of fear conditioning, as assessed 24 hr after training. This deficit could be caused by a failure to learn during acquisition or a failure to consolidate learning in the time after training. To distinguish between these alternatives, we repeated the intra-amygdala study with the addition of a test of STM shortly after training. In this design, the rats again received vehicle or drug either before training or before a test session $24 \mathrm{hr}$ after training, but in addition all rats received vehicle or drug infusions immediately before a STM test that took place $1 \mathrm{hr}$ after training (Fig. 3).

\section{Pretraining infusions}

Rats receiving pretraining infusions of ifenprodil showed impaired STM for both the tone CS and context when tested $1 \mathrm{hr}$ after training, indicating that they failed to learn (Fig. $3 A$ ). The ANOVA for tone STM scores showed a significant effect for group $\left(F_{(2,19)}=69.94 ; p<0.01\right)$, and post hoc $t$ tests showed a significant difference between the vehicle and ifenprodil groups. Both doses of ifenprodil inf used into the amygdala before conditioning induced a pronounced deficit on acquisition compared with controls $(p<0.01)$. The STM data in the context test displayed a similar pattern. The ANOVA showed a significant 
A.

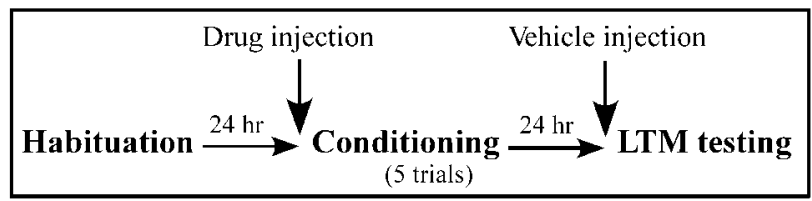

TONE MEMORY CONTEXTUAL MEMORY

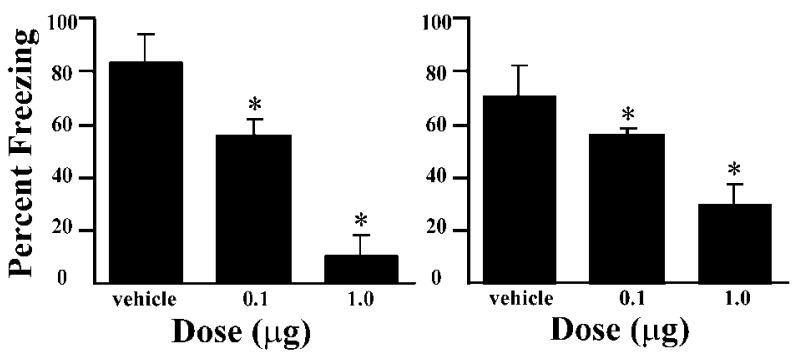

B.

Pretesting Infusions
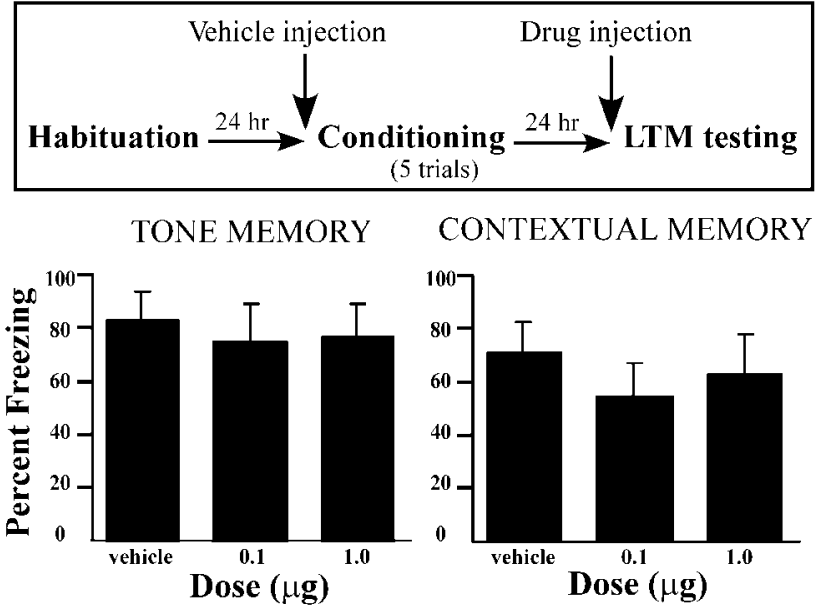

CONTEXTUAL MEMORY

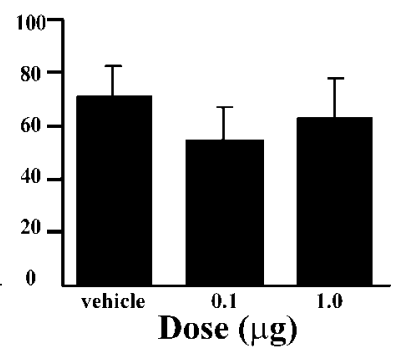

Figure 2. Effects of intra-amygdala infusions of ifenprodil on LTM. $A$, Top, Outline of general behavioral procedures for pretraining intraamygdala infusions of ifenprodil for LTM testing only. Bottom, Mean $( \pm \mathrm{SE})$ percentage freezing for tone and contextual LTM in rats given bilateral intra-amygdala infusions of vehicle $(n=10), 0.1 \mu \mathrm{g}$ of ifenprodil $(n=6)$, or $1.0 \mu \mathrm{g}$ of ifenprodil $(n=8)$ before training. B, Top, Outline of general behavioral procedures for pretesting intra-amygdala infusions of ifenprodil for LTM testing only. Bottom, Mean $( \pm \mathrm{SE})$ percentage freezing for tone and contextual LTM in rats given bilateral intra-amygdala infusions of vehicle $(n=10), 0.1 \mu \mathrm{g}$ of ifenprodil $(n=6)$, or $1.0 \mu \mathrm{g}$ of ifenprodil $(n=8)$ before testing. ${ }^{*} p<0.05$ relative to vehicle.

effect for group $\left(F_{(2,19)}=53.86 ; p<0.001\right)$, and post hoc $t$ tests revealed that the low and high doses of ifenprodil produced a significant decrease in freezing behavior $(p<0.03)$ compared with vehicle controls.

Intra-amygdala infusion of ifenprodil before training also produced a dose-dependent impairment in the LTM of auditory and contextual fear when tested $24 \mathrm{hr}$ after training. The ANOVA for tone LTM scores revealed a significant effect for group $\left(F_{(2,19)}=18.34 ; p<0.01\right)$. Compared with controls, post hoc $t$ tests revealed both doses of ifenprodil induced an impairment in freezing $(p<0.05)$. A similar pattern was found for contextual conditioning, in which the ANOVA showed a signifi- cant effect for group $\left(F_{(2,19)}=6.74 ; p<0.03\right)$, and $t$ tests showed that both doses of ifenprodil caused a deficit in contextual fear conditioning $(p<0.05)$. Thus, intra-amygdala infusions of ifenprodil impair both STM and LTM of fear conditioning, which is consistent with an effect on acquisition rather than on processes related to consolidation.

The vehicle infused controls exhibited somewhat less freezing to the tone CS and context in the LTM test than the vehicle controls in the previous experiment in which there was no STM test inserted between training and LTM testing. This is likely attributable to the occurrence of some fear extinction during the STM test trials in which the subjects were exposed to the CS and context in the absence of the US. Still, the effects of intraamygdala inf usions had a similar effect on LTM as in the previous experiments (Fig. $3 A$ ).

\section{Pretesting infusions}

Animals undergoing pretesting infusions of ifenprodil all received vehicle inf usions before training and drug infusions before STM testing. All groups expressed high levels of freezing to the tone and context during the STM test for tone and context conditioning (Fig. 3B). The ANOVAs for tone and context STM scores showed no significant effects $(p>0.05)$. Similarly, relatively high levels of freezing were also seen in all groups after infusion of ifenprodil or vehicle before testing of LTM for tone and context. The ANOVAs were not significant $(p>0.05)$.

\section{Histology}

Cannula placements for rats in the intra-amygdala infusion experiments are shown in Figure 4. Figure $4 A$ shows the cannula placements for rats in the second experiment that received intraamygdala infusions of ifenprodil followed by a test of LTM. Figure $4 B$ shows the cannula placements for rats in the third experiment that received ifenprodil followed by tests of STM and LTM. Cannula injector tips were observed throughout the rostrocaudal extent of the LA. Only rats with cannula tips at or within the boundaries of LA were included in the data analyses.

\section{DISCUSSION}

In present study, we examined the contribution of the NR2B subunit of the NMDA receptor in the amygdala, especially the LA, to fear conditioning. We determined whether selective blockade of this subunit would interfere with the conditioning of fear to a tone and context paired with footshock. We focused on the LA because it is the sensory gateway into the amygdala, a site of plasticity, and the region in which lesions or reversible functional inactivation prevents fear conditioning from occurring (for review, see Davis, 1997; Fanselow and LeDoux, 1999; Maren, 1999; LeDoux, 2000).

\section{Effects of NR2B blockade on fear conditioning}

Past studies that have examined the effects of NMDA blockade on fear conditioning have mostly used the nonselective antagonist APV (Campeau et al., 1992; Fanselow and Kim, 1994; Maren et al., 1996; Lee and Kim, 1998). Consistent with a role in synaptic plasticity and learning, these studies have found that intraamygdala administration of APV impairs fear conditioning. However, because a number of studies have also found that intraamygdala infusion of APV disrupts fear expression (Maren et al., 1996; Lee and Kim, 1998; Lee et al., 2001), it is not possible to unambiguously conclude that the effects on acquisition are caused by a disruption of plasticity in the amygdala. Indeed, in LA and 
A.

Pretraining Infusions

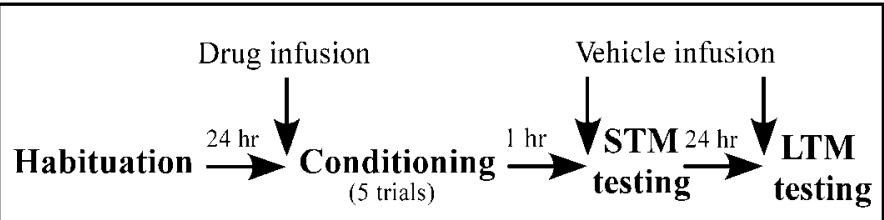

TONE MEMORY

CONTEXTUAL MEMORY

STM
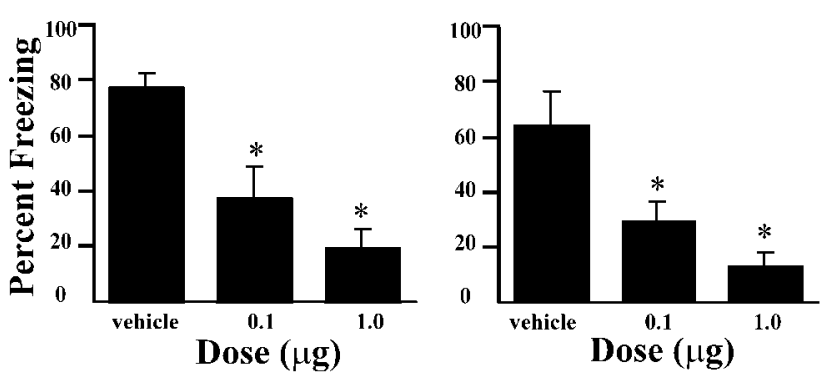

LTM
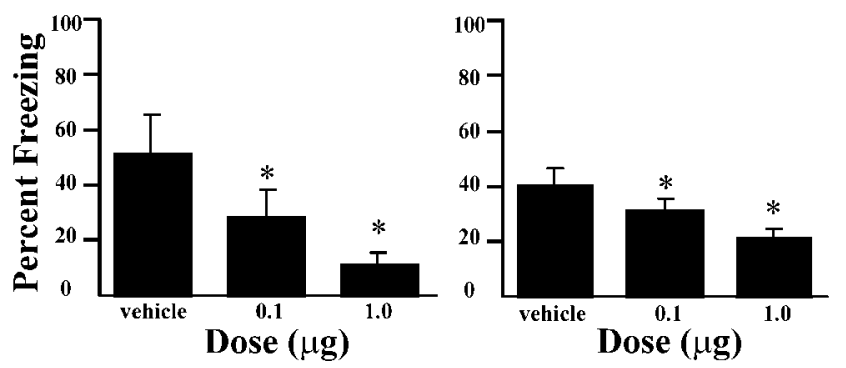

B.

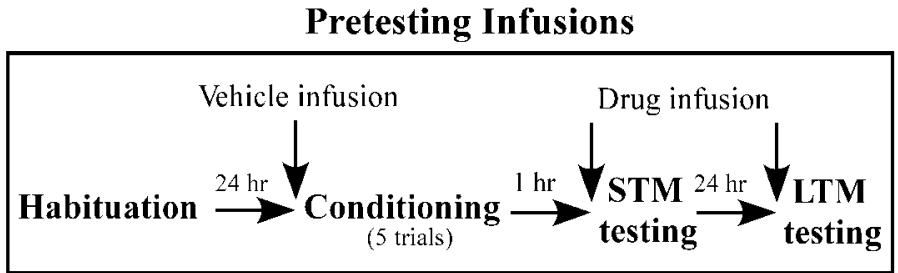

TONE MEMORY

CONTEXTUAL MEMORY

STM
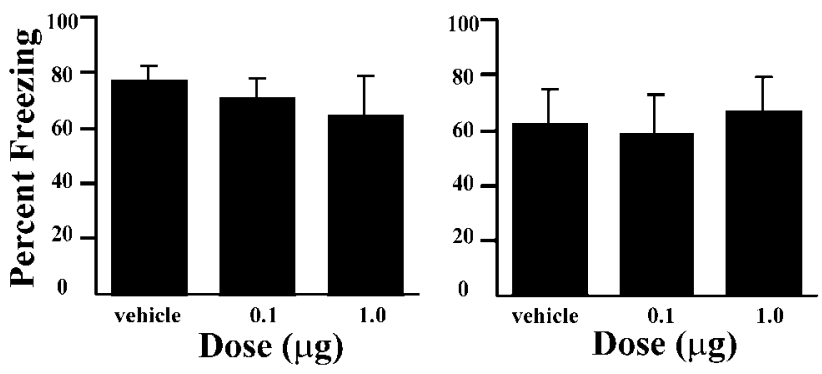

LTM
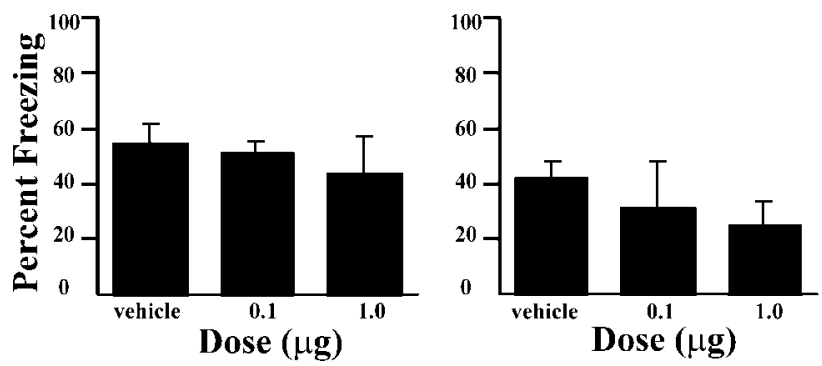

Figure 3. Effects of intra-amygdala infusions of ifenprodil on STM and LTM. A, Top, Outline of general behavioral procedures for pretraining intra-amygdala infusions of ifenprodil for STM testing followed by LTM testing. Bottom, Mean ( \pm SE) percentage freezing for tone (left $t)$ and contextual (right) STM and LTM in rats given bilateral intra-amygdala inf usions of vehicle $(n=8), 0.1 \mu \mathrm{g}$ of ifenprodil $(n=6)$, or $1.0 \mu \mathrm{g}$ of ifenprodil $(n=8)$ before training. $B$, Top, Outline of general behavioral procedures for pretesting intra-amygdala inf usions of ifenprodil for STM testing followed by LTM testing. Bottom, Mean $( \pm \mathrm{SE})$ percentage freezing for tone (left) and contextual (right) STM and LTM in rats given bilateral intra-amygdala inf usions of vehicle $(n=8), 0.1 \mu \mathrm{g}$ of ifenprodil $(n=6)$, or $1.0 \mu \mathrm{g}$ of ifenprodil $(n=8)$ before testing. ${ }^{*} p<0.05$ relative to vehicle.

other amygdala regions, NMDA receptors have been implicated in routine synaptic transmission ( $\mathrm{Li}$ et al., 1995, 1996; Maren, 1996; Weisskopf and LeDoux, 1999). This stands in contrast to the hippocampus, in which the NMDA receptor plays little, if any, role in synaptic transmission (Harris et al., 1984; Bashir et al., 1991; Bliss and Collingridge, 1993; Malenka and Nicoll, 1999). NMDA receptors have also been implicated in LTP in LA and B in some studies (Gean et al., 1993; Huang and Kandel, 1998), although not in all (Chapman and Bellavance, 1992; Watanabe et al., 1995; Li et al., 1998). Thus, it is particularly important that studies examining the role of the amygdala and NMDA receptors in learning and memory and synaptic plasticity control for effects on sensory processing and/or routine transmission. The effect of ifenprodil on the induction and expression of LTP in the LA is an important question that awaits further study.

APV affects all aspects of NMDA channel function (Watkins and Olverman, 1987). Thus, we hypothesized that it might be possible to more easily disrupt fear conditioning without affecting the expression of previously conditioned fear by using an antagonist with partial and selective effects on channel function. Unlike the NR1 subunit, which has been primarily implicated in channel function, the NR2B subunit has been implicated in regulation of channel function (Moyner et al., 1994) and coincidence detection, which is likely to be an important cellular event underlying fear conditioning. In fact, studies of transgenic mice have shown that overexpression of the NR2B subunit throughout the forebrain enhances learning and memory in several tasks, including fear conditioning (Tang et al., 1999). We therefore examined the effects of blockade of the NR2B subunit on fear conditioning by administering the selective antagonist ifenprodil either throughout the brain and body (systemic injections) or directly in the amygdala. Systemic and intra-amygdala injections of ifenprodil before conditioning significantly disrupted acquisition when tested within an hour of training (STM) or 24 hr later (LTM), whereas injections either immediately before the STM test or 24 hr after training and immediately before the LTM test had no effect on the expression of fear conditioning. The fact that both STM and LTM were disrupted in rats that were given pretraining infusions suggests that the NR2B subunit-mediated cellular events that strengthen synapses are initiated rapidly. 
A.

\section{Bregma \\ $-2.7$}

placements from rats infused with vehicle (asterisks), $0.1 \mu \mathrm{g}$ of ifenprodil (circles), or $1.0 \mu \mathrm{g}$ of ifenprodil (squares) before training (black) or before LTM testing only (gray). B, Cannula tip placements from rats infused with vehicle (asterisks), $0.1 \mu \mathrm{g}$ of ifenprodil (circles), or $1.0 \mu \mathrm{g}$ of ifenprodil (squares) before training (black) or before STM and LTM testing (gray). $B$, Basal nucleus; $C E$, central nucleus; $L A$, lateral nucleus.

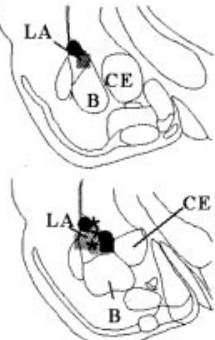

$-3.3$
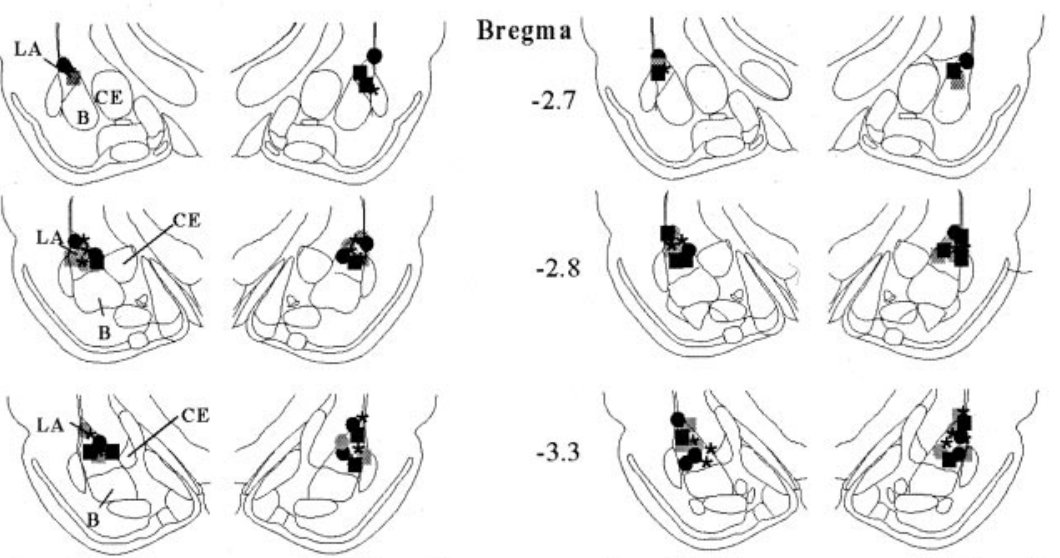

$-3.8$
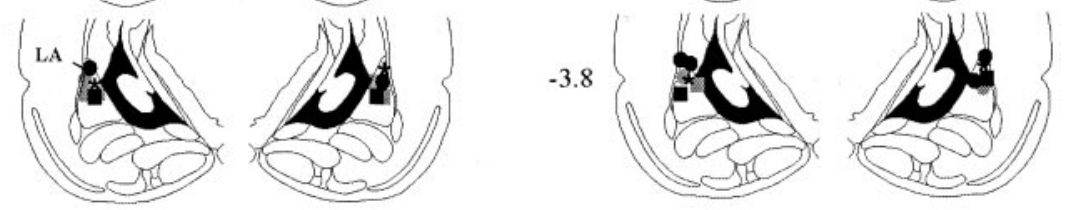

Although cannulas in our experiments were targeted for the LA, by necessity drugs infused into LA will spread to nearby regions, especially the underlying basal nucleus and the nearby central nucleus of the amygdala (CE). Thus, it is not possible from the present results alone to say with certainty that the effects are attributable solely to an action in LA. However, selective infusions of APV into the CE have been shown previously to be without effect on fear conditioning (Fanselow and Kim, 1994). Furthermore, the fact that damage to LA but not the basal nucleus disrupts auditory fear conditioning (Majidashad et al., 1996; Nader et al., 2001) is consistent with the interpretation that infusions in this region have their effects by way of an action in LA.

Although most previous studies using APV have found effects on both acquisition and expression of fear conditioning (Maren et al., 1996; Lee and Kim, 1998; Fendt, 2001; Lee et al., 2001), several studies have found a selective effect on acquisition (Miserendino et al., 1990; Gewirtz and Davis, 1997; Walker and Davis, 2000). These studies each used the fear potentiated startle paradigm to measure fear conditioning. This discrepancy could be attributable to the existence of temporally distinct fear motor centers that mediate the different fear conditioned responses (Lee and Kim, 1998). However, recent studies using the same paradigm have found that both the acquisition and expression of fear-potentiated startle are affected by APV (Fendt, 2001). Although it remains to be determined why APV sometimes has an effect on fear expression and sometimes does not, it is possible that ifenprodil offers a more reliable approach to studies of the role of NMDA receptors in the amygdala and other brain regions in learning and memory.

\section{Functional implications}

Ifenprodil is a subtype-selective NMDA antagonist that antagonizes the NMDA receptor either by causing a modal shift in the gating of the ion pore (Legendre and Westbrook, 1991) or by stabilizing the inactivated form of the ion channel (Reynolds and Miller, 1989). Although both the NR2A and NR2B subunits are involved in channel gating (Moyner et al., 1992), each subunit has different electrophysiological and biochemical properties. The NR1-NR2B complex possesses slower activation and deactivation and thus displays a longer rise and decay time course as compared with the NR1-NR2A complex (Chen et al., 1999). In vitro studies have shown that the NR1-NR2B complex exhibits longer EPSPs than the NR1-NR2A complex (Moyner et al., 1994), allowing a longer time window for coincidence detection in the former. Given that coincidence detection is believed to be an important function performed by NMDA receptors during learning (Tsien, 2000), the NR2B subunit, which is highly prevalent in the brains of juveniles (Sheng et al., 1994; Portera-Cailliau et al., 1996), may be particularly important during plasticity and learning. Indeed, tyrosine phosphorylation of NR2B has been linked with LTP in the hippocampus (Rosenblum et al., 1996; Rostras et al., 1996), as well as to taste learning in the insular cortex (Rosenblum et al., 1997).

One important question is whether or not the NR2B subunit constitutes a major component of NMDA receptor function in the adult rat LA. To this end, we have observed significant expression of the NR2B subunit in the adult rat LA using a subunit-specific antibody (Rodrigues et al., 2000). Moreover, recent studies have shown that the NR2B subunit persists into adulthood, particularly in areas of the brain relevant to cognitive tasks, such as the cortex and hippocampus (Jin et al., 1997; Charton et al., 1999), as well as the thalamus and hypothalamus (Khan et al., 2000). Thus, although NR2B expression does decline after development (Sheng et al., 1994; Portera-Cailliau et al., 1996), it appears that many NMDA receptors express the NR2B subunit well into adulthood (Charton et al., 1999).

Because $1 \mathrm{hr}$ may not be a sufficient time period to initiate gene expression and protein synthesis, the STM results from the present experiments suggest that the NMDA receptor recruits constitutively expressed molecules to fortify the synapse during the initial phases of learning. The NR2B subunit is strongly associated with the enzyme calcium-calmodulin kinase II (CaMKII) (Strack and Colbran, 1998), which has been implicated in synaptic plasticity and memory, including fear condition- 
ing. Specifically, electrophysiological experiments have shown that activation and autophosphorylation of $\alpha \mathrm{CaMKII}$ after $\mathrm{Ca}^{2+}$ influx via NMDA receptors is essential for NMDA-dependent LTP in CA1 of the hippocampus and spatial learning (Giese et al., 1998). In addition, regulated expression of an $\alpha$ CaMKII transgene in the LA and striatum results in impaired fear learning (Mayford et al., 1996). Importantly, the autophosphorylation-dependent targeting of $\alpha \mathrm{CaMKII}$ is specifically linked to the NR2B subunit and not to the NR1 or NR2A subunits (Strack and Colbran, 1998). Furthermore, the recruitment of $\alpha \mathrm{CaMKII}$ into postsynaptic density structures, via association with NR2B, may play a part in the rapid ultrastructural changes found in synapses that undergo LTP (Buchs and Muller, 1996; Strack et al., 2000).

NMDA receptor-mediated plasticity is also necessary for the long-term changes that underlie fear conditioning. In our experiments, blockade of NR2B receptors in the amygdala impaired not only STM, but also LTM of contextual and tone fear. These findings are consistent with those of other studies in the literature that have found NMDA receptor-dependent changes in gene expression in the hippocampus after induction of LTP or acquisition of hippocampal-dependent learning tasks (Cammarota et al., 2000; Davis et al., 2000). Thus, $\mathrm{Ca}^{2+}$ entry through the NMDA receptor appears to play an important role not only in the initial phases of synaptic plasticity and learning, but also in later phases, possibly because of activation of a variety of protein kinase signaling cascades, such as PKA and MAPK, that are known to be essential for both LTM formation of fear and synaptic plasticity in the amygdala (Huang et al., 2000; Schafe and LeDoux, 2000; Schafe et al., 2000).

The present studies suggest that the NR2B subunit of the NMDA receptor plays a distinct role in the plastic changes underlying fear conditioning. Its key role in the acquisition but not the expression of fear memories can perhaps be attributed to the unique electrophysiological and biochemical characteristics of this subunit. These findings have important implications for understanding the role of the NMDA receptor complex in the processes of plasticity and learning in general and open up new possibilities for studying the role of the NMDA receptor in fear learning and synaptic plasticity in the amygdala independently of its role in synaptic transmission.

\section{REFERENCES}

Bashir ZI, Alford S, Davies SN, Randall AD, Collingridge GL (1991) Long-term potentiation of NMDA receptor-mediated synaptic transmission in the hippocampus. Nature 349:156-158.

Bliss TV, Collingridge GL (1993) A synaptic model of memory: longterm potentiation in the hippocampus. Nature 361:31-39.

Buchs PA, Muller D (1996) Induction of long-term potentiation is associated with major ultrastructural changes of activated synapses. Proc Natl Acad Sci USA 93:8040-8045.

Cammarota M, Bevilaqua LR, Ardenghi P, Paratcha G, Levi de Stein M, Izquierdo I, Medina JH (2000) Learning-associated activation of nuclear MAPK, CREB and Elk-1, along with Fos production, in the rat hippocampus after a one-trial avoidance learning: abolition by NMDA receptor blockade. Brain Res Mol Brain Res 76:36-46.

Campeau S, Miserendino MJ, Davis M (1992) Intra-amygdala infusion of the $N$-methyl-D-aspartate receptor antagonist AP5 blocks acquisition but not expression of fear-potentiated startle to an auditory conditioned stimulus. Behav Neurosci 106:569-574.

Chapman PF, Bellavance LL (1992) Induction of long-term potentiation in the basolateral amygdala does not depend on NMDA receptor activation. Synapse 11:310-318.

Charton JP, Herkert M, Becker CM, Schroder H (1999) Cellular and subcellular localization of the 2B-subunit of the NMDA receptor in the adult rat telencephalon. Brain Res 816:609-617.

Chen N, Luo T, Raymond LA (1999) Subtype-dependence of NMDA receptor channel open probability. J Neurosci 19:6844-6854.
Chenard BL, Menniti FS (1999) Antagonists selective for NMDA receptors containing the NR2B subunit. Curr Pharm Des 5:381-404.

Davis M (1997) Neurobiology of fear responses: the role of the amygdala. J Neuropsychiatry Clin Neurosci 9:382-402.

Davis S, Vanhoutte P, Pages C, Caboche J, Laroche S (2000) The MAPK/ERK cascade targets both Elk-1 and cAMP response elementbinding protein to control long-term potentiation-dependent gene expression in the dentate gyrus in vivo. J Neurosci 20:4563-4572.

Fanselow MS, Kim JJ (1994) Acquisition of contextual Pavlovian fear conditioning is blocked by application of an NMDA receptor antagonist D,L-2-amino-5-phosphonovaleric acid to the basolateral amygdala. Behav Neurosci 108:210-212.

Fanselow MS, LeDoux JE (1999) Why we think plasticity underlying Pavlovian fear conditioning occurs in the basolateral amygdala. Neuron 23:229-232.

Fendt M (2001) Injections of the NMDA receptor antagonist aminophosphonopentanoic acid into the lateral nucleus of the amygdala block the expression of fear-potentiated startle and freezing. J Neurosci 21:4111-4115.

Gean PW, Chang FC, Huang CC, Lin JH, Way LJ (1993) Long-term enhancement of EPSP and NMDA receptor-mediated synaptic transmission in the amygdala. Brain Res Bull 31:7-11.

Gewirtz JC, Davis M (1997) Second-order fear conditioning prevented by blocking NMDA receptors in amygdala. Nature 388:471-474.

Giese KP, Fedorov NB, Filipkowski RK, Silva AJ (1998) Autophosphorylation at Thr286 of the alpha calcium-calmodulin kinase II in LTP and learning. Science 279:870-873.

Harris EW, Ganong AH, Cotman CW (1984) Long-term potentiation in the hippocampus involves activation of $N$-methyl-D-aspartate receptors. Brain Res 323:132-137.

Hollmann M, Heinemann S (1994) Cloned glutamate receptors. Annu Rev Neurosci 17:31-108.

Huang YY, Kandel ER (1998) Postsynaptic induction and PKAdependent expression of LTP in the lateral amygdala. Neuron 21:169-178.

Huang YY, Martin KC, Kandel ER (2000) Both protein kinase A and mitogen-activated protein kinase are required in the amygdala for the macromolecular synthesis-dependent late phase of long-term potentiation. J Neurosci 20:6317-6325.

Jin DH, Jung YW, Ko BH, Moon IS (1997) Immunoblot analyses on the differential distribution of NR2A and NR2B subunits in the adult rat brain. Mol Cells 7:749-754.

Khan AM, Stanley BG, Bozzetti L, Chin C, Stivers C, Curras-Collazo MC (2000) $N$-methyl-D-aspartate receptor subunit NR2B is widely expressed throughout the rat diencephalon: an immunohistochemica study. J Comp Neurol 428:428-449.

LeDoux JE (2000) Emotion circuits in the brain. Annu Rev Neurosci 23:155-184.

Lee H, Kim JJ (1998) Amygdalar NMDA receptors are critical for new fear learning in previously fear-conditioned rats. J Neurosci 18:8444-8454.

Lee H, Choi J, Brown T, Kim J (2001) Amygdalar NMDA receptors are critical for the expression of multiple conditioned fear responses. J Neurosci 21:4116-4124.

Legendre P, Westbrook GL (1991) Ifenprodil blocks $N$-methyl-Daspartate receptors by a two-component mechanism. Mol Pharmacol 40:289-298

Li H, Weiss SR, Chuang DM, Post RM, Rogawski MA (1998) Bidirectional synaptic plasticity in the rat basolateral amygdala: characterization of an activity-dependent switch sensitive to the presynaptic metabotropic glutamate receptor antagonist $2 \mathrm{~S}$-alpha-ethylglutamic acid. J Neurosci 18:1662-1670.

Li XF, Phillips R, LeDoux JE (1995) NMDA and non-NMDA receptors contribute to synaptic transmission between the medial geniculate body and the lateral nucleus of the amygdala. Exp Brain Res 105:87-100.

Li XF, Stutzmann GE, LeDoux JE (1996) Convergent but temporally separated inputs to lateral amygdala neurons from the auditory thalamus and auditory cortex use different postsynaptic receptors: in vivo intracellular and extracellular recordings in fear conditioning pathways. Learn Mem 3:229-242.

Majidishad P, Pelli DG, LeDoux JE (1996) Disruption of fear conditioning to contextual stimuli but not to a tone by lesions of the accessory basal nucleus of the amygdala. Soc Neurosci Abstr 22:1116.

Malenka RC, Nicoll RA (1999) Long-term potentiation-a decade of progress? Science 285:1870-1874.

Maren S (1996) Synaptic transmission and plasticity in the amygdala. An emerging physiology of fear conditioning circuits. Mol Neurobiol 13:1-22.

Maren S (1999) Long-term potentiation in the amygdala: a mechanism for emotional learning and memory. Trends Neurosci 22:561-567.

Maren S, Aharonov G, Stote DL, Fanselow MS (1996) $N$-methyl-Daspartate receptors in the basolateral amygdala are required for both acquisition and expression of conditional fear in rats. Behav Neurosci 110:1365-1374.

Mayford M, Bach ME, Huang YY, Wang L, Hawkins RD, Kandel ER 
(1996) Control of memory formation through regulated expression of a CaMKII transgene. Science 274:1678-1683.

Miserendino MJ, Sananes CB, Melia KR, Davis M (1990) Blocking of acquisition but not expression of conditioned fear-potentiated startle by NMDA antagonists in the amygdala. Nature 345:716-718.

Nader K, Majidishad P, Amorapanth P, LeDoux JE (2001) Damage to the lateral and central, but not other, amygdaloid nuclei prevents the acquisition of auditory fear conditioning. Learn Mem 8:156-163.

Nakanishi S (1992) Molecular diversity of glutamate receptors and implications for brain function. Science 258:597-603.

Portera-Cailliau C, Price DL, Martin LJ (1996) N-methyl-D-aspartate receptor proteins NR2A and NR2B are differentially distributed in the developing rat central nervous system as revealed by subunit-specific antibodies. J Neurochem 66:692-700.

Reynolds IJ, Miller RJ (1989) Ifenprodil is a novel type of $N$-methyl-Daspartate receptor antagonist: interaction with polyamines. Mol Pharmacol 36:758-765.

Rodrigues SM, LeDoux JE, Morrison JH (2000) Differential expression of the $N$-methyl-D-aspartate receptor NR2B subunit in the lateral nucleus divisions of the rat amygdala. Soc Neurosci Abstr 26:465.11.

Rosenblum K, Dudai Y, Richter-Levin G (1996) Long-term potentiation increases tyrosine phosphorylation of the $N$-methyl-D-aspartate receptor subunit $2 \mathrm{~B}$ in rat dentate gyrus in vivo. Proc Natl Acad Sci USA 93:10457-10460.

Rosenblum K, Berman DE, Hazvi S, Lamprecht R, Dudai Y (1997) NMDA receptor and the tyrosine phosphorylation of its $2 B$ subunit in taste learning in the rat insular cortex. J Neurosci 17:5129-5135.

Schafe GE, LeDoux JE (2000) Memory consolidation of auditory Pavlovian fear conditioning requires protein synthesis and protein kinase A in the amygdala. J Neurosci 20:RC96(1-5).

Schafe GE, Atkins CM, Swank MW, Bauer EP, Sweatt JD, LeDoux JE (2000) Activation of ERK/MAP kinase in the amygdala is required for memory consolidation of Pavlovian fear conditioning. J Neurosci 20:8177-8187.

Sheng M, Cummings J, Roldan LA, Jan YN, Jan LY (1994) Changing subunit composition of heteromeric NMDA receptors during development of rat cortex. Nature 368:144-147.

Strack S, Colbran RJ (1998) Autophosphorylation-dependent targeting of calcium/calmodulin-dependent protein kinase II by the NR2B subunit of the $N$-methyl-D-aspartate receptor. J Biol Chem 273:20689-20692.

Strack S, McNeill RB, Colbran RJ (2000) Mechanism and regulation of calcium/calmodulin-dependent protein kinase II targeting to the NR2B subunit of the $N$-methyl-D-aspartate receptor. J Biol Chem 275:23798-23806.

Tang YP, Shimizu E, Dube GR, Rampon C, Kerchner GA, Zhuo M, Liu G, Tsien JZ (1999) Genetic enhancement of learning and memory in mice. Nature 401:63-69.

Tsien JZ (2000) Linking Hebb's coincidence-detection to memory formation. Curr Opin Neurobiol 10:266-273.

Walker DL, Davis M (2000) Involvement of NMDA receptors within the amygdala in short- versus long-term memory for fear conditioning as assessed with fear-potentiated startle. Behav Neurosci 114:1019-1033.

Watanabe Y, Ikegaya Y, Saito H, Abe K (1995) Roles of GABAA, NMDA and muscarinic receptors in induction of long-term potentiation in the medial and lateral amygdala in vitro. Neurosci Res $21: 317-322$

Watkins JC, Olverman HJ (1987) Agonists and antagonists for excitatory amino acid receptors. Trends Neurosci 10:265-272.

Weisskopf MG, LeDoux JE (1999) Distinct populations of NMDA receptors at subcortical and cortical inputs to principal cells of the lateral amygdala. J Neurophysiol 81:930-934. 